\title{
Dominique Avon,Karam Rizk (éd.), De la faute et du salut dans l'histoire des monothéismes
}

Paris, Karthala, coll. «Signes des Temps», 2010, 274 p.

Jean-Louis Schlegel

\section{OpenEdition}

\section{Journals}

Édition électronique

URL : http://journals.openedition.org/assr/22974

DOI : $10.4000 /$ assr.22974

ISSN : $1777-5825$

Éditeur

Éditions de l'EHESS

Édition imprimée

Date de publication : 31 décembre 2011

Pagination : 100

ISBN : 9782713223273

ISSN : 0335-5985

Référence électronique

Jean-Louis Schlegel, « Dominique Avon,Karam Rizk (éd.), De la faute et du salut dans l'histoire des monothéismes », Archives de sciences sociales des religions [En ligne], 156 | octobre-décembre 2011, document 156-10, mis en ligne le 14 février 2012, consulté le 21 septembre 2020. URL : http:// journals.openedition.org/assr/22974; DOI : https://doi.org/10.4000/assr.22974

Ce document a été généré automatiquement le 21 septembre 2020.

(c) Archives de sciences sociales des religions 


\title{
Dominique Avon,Karam Rizk (éd.), De la faute et du salut dans l'histoire des monothéismes
}

\author{
Paris, Karthala, coll. «Signes des Temps», 2010, 274 p.
}

\author{
Jean-Louis Schlegel
}

\section{RÉFÉRENCE}

Dominique Avon,Karam RIzK (éd.), De la faute et du salut dans l'histoire des monothéismes, Paris, Karthala, coll. «Signes des Temps», 2010, 274 p.

1 Deux colloques à trois ans de distance, au Liban et en France, sont à l'origine de cet ouvrage sur deux points centraux, et liés, dans les religions monothéistes et dans d'autres. Le sujet est traité, des origines bibliques à nos jours, en quinze chapitres quelque peu juxtaposés et laissant, par leur contenu, de larges plages temporelles entre eux - l'auteur de la réflexion sur la Bible, Michel Dousse, rappelle en outre que celle-ci «couvre plus de deux mille ans d'expériences et de réflexions». Les contributions sont aussi de longueurs assez diverses. Mais qui a publié un colloque (deux en un ici, en l'occurrence) en connaît les aléas. Dans la deuxième étude, Abdellatif Idrissi met en lumière la «notion de péché de la période préislamique au début de l'islam»: le "péché» occupe un vaste champ sémantique dans le texte coranique, et, d'une certaine manière, la difficulté à surmonter sera de passer aux multiples sens issus des traditions tribales à l'idée de «rupture de l'alliance» et d'effacement du péché par le rétablissement du pacte avec Allah. Auparavant, Bardezane d'Edesse, penseur chrétien du III $-\mathrm{IV}^{\mathrm{e}}$ siècle, de langue syriaque - langue dont on sait l'importance pour la formation du discours coranique -, avait posé le problème fondamental de la liberté, dans un vaste système de pensée qui ne subsiste qu'à travers le seul ouvrage laissé par lui. L'Arménie du IV siècle (Gérard Dédeyan), sous influence iranienne, convertie au christianisme, représente un autre jalon de cette histoire: s'y développe une forte conception du martyre pour la foi, 
de combattants et de non-combattants, dans des guerres défensives, c'est-à-dire «justes» au sens de saint Augustin. Louis Boisset souligne simultanément l'importance de l'idée de salut pour l'expansion des croisades et l'ambigüité de ce registre, souvent perdu aujourd'hui, face à des perceptions politico-religieuses très négatives du mot et de la réalité. Paul Rouhana présente l'eschatologie syro-maronite à travers un recueil médiéval de chants liturgiques pour les défunts, et Ahyar Synno les «fins dernières» selon Ibn Taymiyya à travers son ouvrage intitulé Fatāwā («Responsa»): l'eschatologie d'Ibn Taymiyya n'est pas dénuée d'un intérêt actuel, dans la mesure où les salafistes récents et les partisans d'un État islamique le comptent parmi leurs maîtres.

2 Dans l'étude de Jérôme Grondeux, sur les « prophètes romantiques » (Raynaud, Lamennais, Saint-Simon entre autres), apparaît d'abord leur «modernité», ou une facette de la modernité, en ce qu'ils louent la communauté, le sentiment religieux, l'idée d'une sorte de fonds religieux universel «noble», d'une Tradition de l'«humanité» dont les religions particulières ne sont qu'une manifestation. La "pastorale de la peur» au XIX ${ }^{\mathrm{e}}$ siècle (Guillaume Cuchet) revient sur une expression de Jean Delumeau pour en mesurer la portée après la Révolution, et l'auteur conclut, entre trois thèses différentes sur le sujet, que la «pastorale de la peur (...) connaît un premier rééquilibrage dans le sens d'une déflation du "péché" par rapport au "pardon"». L'auteur pense cependant qu'on peut toujours parler d'une «pastorale de la crainte», qui finit par s'effacer vers la seconde moitié du xx ${ }^{e}$ siècle. Le travail de Jean-Pierre Chantin («Le discours sur la grâce et la faute originelle dans le jansénisme tardif») pourrait s'articuler au précédent, en ce qu'il montre le recul du jansénisme si puissant avant la Révolution, ou comment il est sur la défensive et en opposition "gallicane» à l'ultramontanisme triomphant qui, de son côté, «évolue» quelque peu sur le péché et la rigueur du pardon, après la «mansuétude» envers le pécheur prêchée par Alphonse de Liguori. L'évolution de la psychiatrie (Hervé Guillemain) dans les années 1860 n'est sans doute pas pour rien non plus dans une autre évaluation de la faute. Alors que le discours sur l'origine morale de la faute bat encore son plein au début de la décennie - il est même à son apogée -, son déclin sera très rapide dans les années suivantes, et on cherchera à définir des pathologies précises qui n'ont plus rien à voir avec une culpabilité. D'une certaine manière, l'évolution des catéchismes protestant et catholique aux $\mathrm{XIX}^{\mathrm{e}}$ et $\mathrm{XX}^{\mathrm{e}}$ siècles (très bonne mise au point de Paul Airiau) ne fait que refléter le recul au sens large de la notion de «faute»; elle témoigne non seulement de la difficulté pour en redessiner les contours avec d'autres mots, mais des lézardes qui sont ainsi ouvertes dans l'ensemble du système théologique chrétien de la rédemption, la pensée orthodoxe russe (en particulier la notion de péché originel) n'étant pas épargnée par ces tribulations (Franck Damour). À certains égards, l'étude sur Moussa Sadr, leader chiite libanais disparu en... Lybie lors d'une visite officielle en 1978 - confirme ce désarroi aussi en pays d'islam: Sadr inscrit son action politique contre le «mal collectif» dans la ligne de l'eschatologie chiite, tout en peinant à désigner clairement des responsables (hormis Israël). Dominique Avon revient in fine sur une polémique qui défraya en son temps la chronique catholique: une réinterprétation de la résurrection chrétienne, donc du salut chrétien, par le $\mathrm{P}$. Xavier Léon-Dufour, exégète déjà très connu, dans un livre intitulé Résurrection de Jésus et message pascal (Seuil, 1971). Avon restitue avec précision le «nœud» et les termes du débat, les interventions pour et contre les thèses de LéonDufour. Il est frappant que dans cette querelle post-Vatican II précoce, reviennent tous les arguments de la controverse théologique classique et s'annoncent ceux qui seront toujours utilisés par la suite contre les «modernistes», mais aussi des divisions du 
travail nouvelles (entre l'exégèse et la théologie, mais aussi entre toutes deux et la philosophie la plus contemporaine). Au centre du «nœud» théologique demeure en fin de compte une question des plus permanentes: qu'est-ce qu'un «corps» humain de chair, et que signifie un corps humain, «pécheur» mais «sauvé»? 